\title{
Carbon cycle research after Kyoto
}

By PIETER P. TANS ${ }^{1 *}$ and DOUGLAS W. R. WALLACE $2 \dagger,{ }^{1}$ Climate Monitoring and Diagnostics Laboratory, National Oceanic and Atmospheric Administration, Mailcode R/E/CG1, 325 Broadway, Boulder, CO 80304, USA; ${ }^{2}$ Department of Applied Science, Brookhaven National Laboratory, PO Box 5000, Upton, NY11973-5000, USA

(Manuscript received in final form 26 October 1998)

\section{ABSTRACT}

Recent progress in research of the global carbon cycle is reviewed and research needs for the immediate future are discussed, in light of the challenge posed to society to come to grips with the problem of man-made climate change. The carbon cycle in the oceans and on the land is reviewed, and how the atmosphere functions to couple them together. Major uncertainties still exist for any projection of the future atmospheric burden of carbon dioxide resulting from postulated emission scenarios of $\mathrm{CO}_{2}$. We present some ideas on how future policies designed to limit emissions or to sequester carbon can possibly be supported by scientific evidence of their effectiveness.

\section{Introduction}

During the last decade there has been significant progress in carbon cycle research, which was evident at the 5th International Carbon Dioxide Conference held in Cairns, Australia on 8-12 September 1997. Measurements of atmospheric $\mathrm{CO}_{2}$, of the oceanic carbon system, in ice cores and firn, measurements in terrestrial ecosystems, of isotopic ratios and of $\mathrm{O}_{2} / \mathrm{N}_{2}$ in air, and hypotheses and models attempting to link together different pieces of the puzzle have all contributed.

The world has a keen interest in understanding the carbon cycle as any serious policy to minimize or slow global warming has to consider the fate of the $\mathrm{CO}_{2}$ emitted by man into the atmosphere.

* Corresponding author.

$\dagger$ Present address: Abteilung Meereschemie, Institut für Meereskunde an der Universität Kiel, Duesternbrooker Weg 20, D-24105 Kiel, Germany.
There are two general issues. Firstly, we need to gain a better scientific understanding of the global carbon cycle. This will be helpful in defining emission targets with the aim to keep atmospheric $\mathrm{CO}_{2}$ below certain agreed-upon levels. Secondly, there will be a need to assess the effectiveness of specific policies designed to sequester carbon, for example through forestry management, as well as a need to monitor national emissions by independent means.

\section{Scientific understanding of the carbon cycle}

How rapidly, and by how much, need $\mathrm{CO}_{2}$ emissions be reduced in order to keep future anthropogenic climate forcing below a certain level? Two general questions immediately come to mind:

- What has happened to the $\mathrm{CO}_{2}$ that has been emitted already? 
- What will be the future atmospheric $\mathrm{CO}_{2}$ loading resulting from past and future emissions?

Recent progress has been mostly relevant to the first question. Without a satisfactory answer to the first question no one would have much confidence in any answers to the second, which is much more difficult than the first.

Unlike other chemical species involved in the earth's radiation balance such as methane or nitrous oxide, it is not useful to think in terms of some finite atmospheric lifetime for $\mathrm{CO}_{2}$. A greenhouse gas like methane is photochemically oxidized in the atmosphere, on average in about 9 years. The atmosphere thus continually cleanses itself of methane in that amount of time. Carbon dioxide may dissolve in ocean waters, the carbon may get turned into wood during plant growth, but in general it turns back into atmospheric $\mathrm{CO}_{2}$ easily, and does so in huge amounts. For $\mathrm{CO}_{2}$ it is more appropriate to think in terms of chemical equilibria relevant to the global carbon cycle, with carbon being exchanged relatively rapidly between the atmosphere, oceans, and plants/soils. There is much more carbon contained in the huge geological reservoirs of carbonate rock and kerogen, but the exchange between these and the rapid reservoirs is exceedingly slow. Therefore, the $\mathrm{CO}_{2}$ produced by the burning of fossil fuels is, on the timescale of civilizations, "stuck" in the combined system of the atmosphere, the oceans, and plants and soils. Left to itself, a kind of near-steady state develops between these three reservoirs of carbon, with enormous and continuing bi-directional flows between the atmosphere and each of the two other reservoirs.

In the remainder both the oceanic and terrestrial sinks are addressed. There is a fundamental difference between those two with regard to greenhouse gas policies. The oceans remain the biggest longterm player in the carbon cycle, and any research program that neglects the oceans is doomed to be nearly irrelevant for policy. We are not likely to have a directed, purposeful influence on $\mathrm{CO}_{2}$ uptake by the oceans, however. The terrestrial biosphere on the other hand is already being manipulated by us on a global scale, and its influence on atmospheric $\mathrm{CO}_{2}$ is substantial. The effect on the carbon cycle of our ecological interventions has thus far been mostly inadvertent.
This is not likely to remain so, as was already evident at the Kyoto negotiations.

\subsection{The fate of $\mathrm{CO}_{2}$ emitted until now}

Historical changes of the quasi-steady state of the carbon system are clearly reflected in ice core and isotopic records, which also record the dramatic and unprecedented changes caused by anthropogenic $\mathrm{CO}_{2}$ emissions (Raynaud, 1993). Atmospheric $\mathrm{CO}_{2}$ is higher today by about $30 \%$ than at any time during the last several hundred thousand years (J.-M. Barnola et al., 1997). Furthermore, most of the increase occurred during the second half of the 20th century, coinciding with the combustion of fossil fuels. On average at least half of the emitted $\mathrm{CO}_{2}$ did not remain in the atmosphere. The IPCC assessment has summarized the state of our knowledge in this area: during the decade of the 1980s the oceans absorbed $2.0 \pm 0.8 \cdot 10^{15} \mathrm{~g} \quad(\mathrm{Pg}) \mathrm{C} \mathrm{yr}^{-1}$, and terrestrial ecosystems stored globally $1.8 \pm 1.6 \mathrm{Pg} \mathrm{C} \mathrm{yr}^{-1}$ (Schimel et al., 1996). The latter approximately compensated for the estimated loss due to biomass burning of $1.6 \pm 1.0 \mathrm{Pg} \mathrm{C} \mathrm{yr}^{-1}$, so that the global net storage in ecosystems was close to zero. This picture is gradually coming into sharper focus.

The atmospheric inventory increase on a global scale is accurately known on the basis of direct measurements because the atmosphere is rapidly mixed. The oceanic uptake term is currently inferred from models that have been indirectly calibrated or validated with tracer observations. The tracers used (e.g. bomb radiocarbon, tritium, CFCs) are imperfect analogs for fossil fuel $\mathrm{CO}_{2}$ and data are relatively sparse. Ocean models inevitably also have some limitations in the way ocean circulation and mixing is represented. Therefore it is imperative to independently assess oceanic uptake via measurement. During the WOCE/JGOFS program an enormous amount of ocean data has been gathered, which is now beginning to be analyzed and synthesized. The penetration of anthropogenic carbon and its inventory in different parts of the oceans can be much better estimated than before, through the analysis of correlated data on carbon, nutrients, oxygen, and physical variables, separating natural variability from anthropogenic changes. This can be done using so-called "preformed $\mathrm{CO}_{2}$ " calculations (Gruber et al., 1996. The first such analysis, 
for the Atlantic Ocean, has been published: Gruber, 1998) or in a more purely statistical way by examining, for specific ocean basins, changes over time of the correlation between chemical species (Wallace et al., 1995). Both methods should be pursued because they are somewhat independent, and because they address different time scales. The former gives an estimate of the anthropogenic $\mathrm{CO}_{2}$ invasion since pre-industrial times, the latter an estimate of the increase since the GEOSECS expeditions of the 1970s.

Spatial interpolation techniques, based on correlating carbon and physical variables, and the high density of physical observations, coupled with estimates of water mass transports allow the estimation of the fluxes of carbon within and between ocean basins (Brewer et al., 1989; Holfort et al., 1998). This permits separate assessments of the transport of both natural and anthropogenic carbon components in the ocean which can be compared with $\mathrm{CO}_{2}$ transport via the atmospheric circulation to infer regional distributions of largescale sources and sinks for anthropogenic carbon. The distributions can then be compared to the surface delta- $f \mathrm{CO}_{2}$ method (see below).

The net exchange of carbon between surface waters and the atmosphere can be constrained with new and better data of the fugacity $(\approx$ partial pressure) difference between the air and the water (Takahashi et al., 1997). Currently the weakest element of this approach is our poor understanding of the kinetics of the process of air-sea gas exchange. For instance, if the exchange velocity were to depend more non-linearly than we currently believe on variables correlated with wind speed, the high latitudes would gain in relative importance. Another important issue is the interannual variability of the $\mathrm{CO}_{2}$ fugacity in surface waters. Time series of atmospheric $\mathrm{CO}_{2}$ and $\delta^{13} \mathrm{C}$ data (especially Keeling et al., 1995; and to a lesser extent Francey et al., 1995) seem to imply enormous variations, something that most oceanographers feel uncomfortable with, given (sparse) ocean surface observations thus far. The problem partially results from the assumption that the global picture is represented by the very few atmospheric observation sites involved (Rayner et al., 1999, in the case of Cape Grim). It is time to determine through measurements a much better parameterization of the exchange velocity, so that observations of the atmosphere can be truly informative for oceanographic issues and vice versa. Small, but large-scale gradients of the atmospheric $\mathrm{CO}_{2}$ concentration are driven by surface sources and sinks, and could be, for example, an important constraint on $\mathrm{CO}_{2}$ uptake by the Southern Oceans. As atmospheric transport models continue to improve, this constraint will become more compelling.

Long-term ocean time-series which include detailed biogeochemical and $\mathrm{CO}_{2}$ measurements are improving our mechanistic understanding of the processes affecting ocean-atmosphere carbon uptake and partitioning. Time-series data sets from Bermuda and Hawaii are being used to develop model parameterizations of ocean biogeochemical processes affecting the ocean carbon cycle (Doney et al., 1996; Fasham, 1995). They are increasingly being used as test-beds for novel highresolution measurement instruments. Notable findings from the time-series sites include an increased awareness of the complexity of the ocean's nitrogen cycle (Karl et al., 1997) which has the potential to alter our view of the sensitivity of atmospheric $\mathrm{CO}_{2}$ concentrations to biological processes in the ocean (Falkowski, 1997). The time-series sites are also one of the few locations where seasonal variations in upper ocean C-13 concentrations are measured (Bacastow et al., 1996). Such time-resolved information is critical for correctly interpreting the large "snapshot" data sets collected along ocean transects.

The current time-series sites are, however, located predominantly in the ocean's sub-tropical gyres where the largest driving force for air-sea $\mathrm{CO}_{2}$ exchange is seasonal temperature changes and where there is relatively little exchange of properties between the atmosphere and the deep ocean. There is a pressing requirement to establish related time-series data sets in high latitude environments where the potential for complex biologically-driven $\mathrm{CO}_{2}$ changes is larger, and where there is more intimate contact between the atmosphere and the deep ocean. Candidate locations such as the Labrador Sea, the Southern Ocean or the waters off Iceland as well as coastal or equatorial upwelling zones should be considered as enhancements to the time-series network.

The large ocean data sets collected in recent years under the auspices of WOCE, JGOFS, OACES, and other programs will, assuming suitable data-analysis is carried out, give a much 
better definition of where the current oceanic sinks are, and how that carbon is redistributed in the ocean's interior. The Atlantic data (Gruber, 1998) and a preliminary synthesis of the $\mathrm{CO}_{2}$ Survey Indian Ocean data (C.L. Sabine, personal communication) shows that there can be large regional discrepancies between observed and modeled penetration of anthropogenic carbon. Whether these differences simply average to zero over the ocean as a whole such that the model-derived estimates of global ocean $\mathrm{CO}_{2}$ uptake are reasonably accurate remains an open question that can only be answered through further data analysis. However it is already clear that the observed penetration of anthropogenic $\mathrm{CO}_{2}$ can provide, through detailed comparison with models, the basis and impetus for improving models of oceanic $\mathrm{CO}_{2}$ uptake.

We should expect, at minimum, that the error bars of global ocean uptake will narrow considerably in the next five years. We may also have to revise the currently accepted best-estimate of $2 \mathrm{Pg} \mathrm{C} /$ year. Mass balance considerations alone would then provide at least a good global estimate of the net carbon gain (or loss) by terrestrial ecosystems. Further, ocean carbon transport estimates can provide coarse-scale resolution of the location of anthropogenic vs. natural carbon sinks in the ocean which will further constrain inferences of terrestrial sink distributions based on atmospheric data (see for example Broecker and Peng, 1992; Keeling and Peng, 1995; Holfort et al., 1998).

However, also on the land we need to find out in more spatial detail where the sinks are, and in general how human land use is quantitatively affecting the carbon cycle, for example through deforestation and agriculture. Already atmospheric data, when interpreted with numerical models of atmospheric transport, point to a significant $\mathrm{CO}_{2}$ sink on the land at temperate latitudes in the northern hemisphere, and possibly in North America in particular (Fan et al., 1998). Thus far it has proven hard to confirm the mid-latitude sink through census data of forest carbon and soil carbon stocks (Dixon et al., 1994). For example, we don't know very well the carbon balance of any major ecosystem in the US, which has been relatively well researched and documented compared to most other parts of the world. One component that had been overlooked thus far is terrestrial sedimentation. It had always been assumed that the soil carbon subject to accelerated erosion, for example due to agriculture, is fully oxidized to $\mathrm{CO}_{2}$. The majority of this material including the carbon is buried in reservoirs, wetlands, etc. This could amount globally to 0.6-1.5 $\mathrm{Pg} \mathrm{C} \mathrm{yr}^{-1}$ (Stallard, 1998).

The case of the atmospheric data has been strengthened further by new measurements of the ${ }^{13} \mathrm{C} /{ }^{12} \mathrm{C}$ ratio of $\mathrm{CO}_{2}$ (Ciais, 1995), which especially improved the spatial definition of ${ }^{13} \mathrm{C} /{ }^{12} \mathrm{C}$, and of the atmospheric oxygen to nitrogen ratio (Keeling and Shertz, 1992; Bender et al., 1996). Both of the latter two measurements can be used to distinguish between oceanic and terrestrial $\mathrm{CO}_{2}$ uptake. The interpretation of the isotopic data is subject to substantial uncertainty about the extent of purely isotopic exchange, often called the isotopic disequilibrium flux, which always occurs with or without an accompanying net exchange of total carbon (Tans, 1993). A better determination of the air-sea gas exchange velocity is especially important to pin down the isotopic disequilibrium flux. The isotopic signature of terrestrial primary productivity, strongly influenced by the relative proportions of the C-3 and C-4 photosynthetic pathways, needs to be better defined as well (Lloyd and Farquhar, 1994; Fung et al., 1997). The atmospheric oxygen budget may be subject to uncertainties about decadal variations in the ventilation of deeper, oxygen-poor waters. It is nevertheless encouraging that the isotopic and the $\mathrm{O}_{2} / \mathrm{N}_{2}$ methods are in approximate agreement.

The ${ }^{18} \mathrm{O} /{ }^{16} \mathrm{O}$ isotopic ratio of $\mathrm{CO}_{2}$ has not yet been used much in carbon cycle studies. It offers the potential to distinguish between photosynthesis and respiration in terrestrial ecosystems (Francey and Tans, 1987; Hesterberg and Siegenthaler, 1991; Farquhar et al., 1993; Ciais et al., 1997a,b). The oxygen isotopes of $\mathrm{CO}_{2}$ equilibrate with those of liquid water in soils (respiration) and in leaves (photosynthesis). Water in leaves is generally enriched in ${ }^{18} \mathrm{O}$ relative to soil water. A prerequisite for this approach is good information on the isotopic patterns associated with the hydrological cycle. Several numerical models of atmospheric dynamics now explicitly incorporate photosynthesis and a soil water budget because it exerts a major influence on surface energy exchange over the land, thus coupling the carbon budget to the hydrological cycle 
(Denning et al., 1995; Bonan, 1998). It could be revealing to add $\delta^{18} \mathrm{O}$ to this coupling.

The increase in amplitude of the seasonal cycle of $\mathrm{CO}_{2}$ (Myneni et al., 1997), and especially the earlier onset of the photosynthetic drawdown, is consistent with net uptake by terrestrial systems at temperate and high latitudes in the northern hemisphere (Randerson et al., 1997).

New micrometeorological (eddy-covariance) methods have been developed to measure ecosystem exchange of trace gases, on a spatial scale of hundreds of meters (Wofsy et al., 1993; Baldocchi et al., 1996). Such measurements, especially in conjunction with climatic, plant physiological, ecological, and soil data, are used to investigate mechanisms responsible for uptake or loss. Relationships with climatic variables have been found (Goulden et al., 1996, 1998). The managable spatial scale facilitates the search for mechanisms, but makes it necessary to test extrapolations to regional scales with other methods. Ecosystem manipulations, such as the Free Air $\mathrm{CO}_{2}$ Enhancement (FACE) projects, will give us insight in the physiological, ecosystem, and biogeochemical cycling response to higher atmospheric $\mathrm{CO}_{2}$. Similarly for the controlled deposition of nitrogen and ozone. These projects are coordinated by the Global Change and Terrestrial Ecosystems (GCTE) project of the International Geosphere-Biosphere (IGBP) Program. The spatial scale of each of these experiments is small, however.

How to scale up from process measurements to areas large enough to be meaningful in terms of national and global carbon budgets is a great experimental challenge. Extrapolations to large spatial scales are now performed with ecosystem and climate models, but these models have mostly been only compared to each other (Rastetter, 1996). We will have to extract our information about large-scale sources and sinks from atmospheric observations. Concentration measurements upwind and downwind of an area should reflect how much $\mathrm{CO}_{2}$ (or other stable trace gas) has been added to, or removed from, the atmosphere in the area between the obvervations. It is essential to gather data in the vertical dimension (Tans et al., 1996) because atmospheric mixing processes are complex, especially over the land. How the signal from surface sources manifests itself in the atmosphere depends strongly on the stability of the atmospheric boundary layer and on exchange between the free troposphere and the boundary layer.

For the interpretation of observations of the $\mathrm{CO}_{2}$ mole fraction in terms of surface sources and sinks it is imperative that the transport models not only portray the large scale circulation accurately, but also parameterize subgrid scale mixing correctly, in particular for the boundary layer. The recent TRANSCOM exercises show that significant improvement in both categories is sorely needed (Law, 1996; Denning, 1999). Since the atmospheric signature of low latitude sources is weak, due to vigorous vertical mixing, and because there are no relevant observations in important areas (such as over tropical forests), the models work currently roughly as follows. Sources and sinks are derived from observed concentration patterns with some degree of confidence for the temperate and high latitudes, and those for the low latitudes then follow essentially from global mass conservation.

Ecosystem models have to go beyond simulating potential vegetation by incorporating realistic treatments of land use. They will have to tackle the issue of disturbance and transient responses (including evolving species composition) rather than equilibrium patterns. Once their simulated sources and sinks have been translated by atmospheric transport models into concentration patterns, they can be tested against accurate measurements of atmospheric concentration patterns on a regional scale. It is likely that such a strategy will first uncover the relatively short-term response of ecosystems to year-to-year variability of climatic forcing factors. An understanding of such responses will permit a sharper view of underlying trends, and possible changes in those. We should be prepared for the likely possibility that decadal responses to changing forcings are different from interannual responses. Since the competitive relationships between species are affected by global change we may expect changes in the species composition of ecosystems over a decade and longer.

\subsection{Future atmospheric $\mathrm{CO}_{2}$ levels}

There are grounds for optimism that during the coming five years we will be able to ascertain the fate of $\mathrm{CO}_{2}$ already emitted with reasonable accu- 
racy in the oceans. With respect to the land, we still have to contend with the enormous gap in spatial scale between flux and process measurements and the large-scale patterns in the atmosphere. However, it does not follow from section 2.1 that we can have any confidence in predictions of the atmospheric $\mathrm{CO}_{2}$ level into the future. The future $\mathrm{CO}_{2}$ concentration trajectories calculated by the IPCC for a number of postulated scenarios of fossil fuel burning all share the same crucial assumption that the future carbon cycle will keep operating exactly as we understand it has done in the past. This is highly unlikely. Climate change could well lead to substantial changes in ocean circulation, which would immediately affect the way the anthropogenic $\mathrm{CO}_{2}$ is exchanged between the atmosphere and the oceans (Sarmiento and LeQuéré, 1996). As one example, deep water formation in the North Atlantic ocean appears to have been turned on and off a number of times during our current epoch of recurring ice ages (Broecker, 1997).

A second fundamental (at this stage) uncertainty concerns the operation of the so-called biological pump. Atmospheric $\mathrm{CO}_{2}$ is always trying to equilibrate with surface waters, not with the deep oceans. Photosynthesis by organisms in the sunlit layer keep the $\mathrm{CO}_{2}$ concentration of the surface waters substantially lower than the deep. Without photosynthesis in the oceans, and assuming no other surface changes due to organisms (such as calcification), the atmospheric $\mathrm{CO}_{2}$ concentration would be between 900 and $1000 \mu \mathrm{mol} / \mathrm{mol}$. If, on the other hand, photosynthesis would continue everywhere until all of the plant nutrients were fully depleted in all surface waters, atmospheric $\mathrm{CO}_{2}$ would be between 110 and $140 \mu \mathrm{mol} / \mathrm{mol}$. This illustrates the power of the biological pump. The actual pre-industrial $\mathrm{CO}_{2}$ concentration was $280 \mu \mathrm{mol} / \mathrm{mol}$. Surface nutrients are fully depleted in warm and temperate waters but not at high latitudes. In those areas there is less sunlight, biological processes are slower because of low temperatures, there is less time for the growth of organisms because surface water is mixed back into deeper layers more quickly, and the availability of micronutrients such as iron could be a factor (De Baar et al., 1995). The middle two factors are intimately connected with the circulation, but all four factors are subject to climate change (the first through cloud cover, the last through deposition of dust).

Similarly for the continents, as long as we don't know the whereabouts nor the reasons for the current land sink of $\mathrm{CO}_{2}$, we have no idea of how much longer it may continue, or whether it could turn into a source instead. Unlike in the oceans, carbon storage on land is very much subject to direct human intervention. The recent Kyoto climate change negotiations included the possibility of harnessing photosynthesis on land to offset some of the fossil fuel emissions.

\section{What can carbon cycle science do?}

Given the difficulties of obtaining robust and credible predictions of trends in carbon storage under conditions of global change both on land and in the oceans, what can we do? We should not promise ourselves, nor society at large, that we will soon have an earth system model capable of predicting with good credibility atmospheric $\mathrm{CO}_{2}$ levels a century from now for given scenarios of fossil fuel combustion. That would be an impossibly difficult task. The best general strategy is perhaps to monitor ongoing changes in such a way that, firstly, developing trends are picked up quickly, and that, secondly, we have enough information to be able to test hypotheses about their causes. To keep track of carbon and gain fully credible results we will have to rely on a number of independent observational approaches. In the atmosphere and oceans we can measure the changes in inventory, whereas at the air-sea and air-biosphere boundaries we can measure the fluxes. The latter have to be extrapolated with process models and satellite data. Spatial patterns of the $\mathrm{CO}_{2}$ mole fraction in the atmosphere reflect the regional surface sources and sinks. Transport in the oceans must be consistent with inventory changes and air-sea fluxes. Terrestrial inventories, including soil carbon, will have to be consistent with fluxes inferred from atmospheric data.

We will have to build our understanding (and our models) as the global experiment unfolds. We should expect surprises. The negotiation and enactment of greenhouse gas policies will be an ongoing process, and it is likely that requirements and optimum strategies will have to be revised as knowledge improves about the climate system and 
about biogeochemical cycles. Given the importance of energy to society and the long delays involved in changing the energy infrastructure, the process of developing effective greenhouse gas policies will need all the early warning it can get of developing carbon cycle trends.

Some specific research questions relevant to developing trends are suggested, in particular related to the long-term partitioning of carbon between the oceans and the atmosphere. Is there any evidence that the $\mathrm{C} / \mathrm{N}$ and $\mathrm{C} / \mathrm{P}$ ratios of marine production are changing? Can we discern trends in the preformed nutrients of deep water masses? Is the cycling of organic matter in the upper ocean affected by increasing $\mathrm{CO}_{2}$ ? Since the great size of the ocean carbon reservoir dictates the (long-term) isotopic composition of atmospheric carbon, it is important for the interpretation of the isotopic record to determine whether isotopic fractionation during oceanic photosynthesis is changing, perhaps as a result of increasing dissolved $\mathrm{CO}_{2}$. Is there a trend in alkalinity? Equally important are any changes in ocean circulation, especially rates of deep water formation, but those are not specific carbon cycle issues.

On the land the most important issue is probably the long-term influence of human land management on carbon stocks, including those in soils and sediments. There appears to be a sink at temperate latitudes, but what is it being caused by? What determines allocation to, and turnover times of the various carbon pools, and do they exhibit trends?

\section{Verification of treaty obligations and assessment of land use policies}

When nations agree to keep their emissions of specific compounds below certain ceilings there will need to be measurement techniques and strategies capable of providing independent and objective assessments of the emissions inventories arrived at by national census techniques. In the case of carbon dioxide, claims will be made that reforestation, or certain land use practices in general, lead to the sequestration of carbon, and should be counted as negative emissions against a maximum allowed under a treaty. How can we verify the magnitude of such sequestration? If we don't we can expect to soon face the problem of a huge "missing source" of $\mathrm{CO}_{2}$.

Because of the potentially enormous economic consequences any methodology and any data relevant to this issue will be severely challenged. The credibility of the data has to be impeccable. They will need to be tamper-proof, completely open to all challengers (including data that are deemed to be poor or invalid), well-calibrated, and confirmed through independent methods to the maximum extent feasible. Apart from some legal overtones, these are requirements indistinguishable from good experimental scientific practice. Any enforcement of emissions limitations (penalties, credits, etc.) needs to be scrupulously separated from the fact-finding mission in order to safeguard the credibility of the data. Similarly, methods to interpret the data need to be generally accepted. This implies that they have been tested and described in the scientific literature, compared to alternative methods, and will likely be gradually improved. In other words, measurements and interpretations geared towards good verification and assessment are hardly different from good science, and have the potential to greatly contribute to a better understanding of the biogeochemical cycles. In turn, the latter provides crucial information for improving policies dealing with global climate change. Governments will need scientific expertise within their own countries to assess the scientific evidence, and therefore the scientific community responsible for the measurement and modeling program will need to be truly international.

One approach to estimate emissions from atmospheric data is based on correlated variation between different species. If the emission of one compound is known to good accuracy, others can be estimated from their ratio relative to the known one. This at least captures the part of the unknown emissions that is approximately co-located with those of the known compound. We will need an absolute method as well. For fossil fuel combustion there is one property that is a (very nearly) unambiguous telltale: the lack of carbon-14. A measurement of $\mathrm{C}-14$ in $\mathrm{CO}_{2}$ to a precision of 1 permil $(0.1 \%)$ determines the (very) recently added fossil fraction of that $\mathrm{CO}_{2}$ to a precision of $0.3 \mu \mathrm{mol} / \mathrm{mol}$. Although much higher in episodes, we estimate the general enhancement of $\mathrm{CO}_{2}$ due to fossil fuel combustion in the atmospheric boundary layer 
over much of rural North America to be several $\mu \mathrm{mol} / \mathrm{mol}$ (Bakwin et al., in press).

Atmospheric sampling of $\mathrm{CO}_{2}$ from aircraft and at so-called background sites will, when combined with other tracers, such as $\mathrm{CO}, \mathrm{SF}_{6}$, and especially C-14, put constraints on fossil fuel emissions for relatively large regional areas. Air sampling from tall $(200-600 \mathrm{~m})$ towers offers the possibility for emissions verification on an intermediate spatial scale, from tens to a few hundred $\mathrm{km}$. It may be possible to use back-trajectory analysis using meteorological data assimilated by a meso-scale model, combined with a one-dimensional model of vertical mixing, also based on observed meteorological variables, to estimate the continuing evolution of the tower "footprint". This leads to estimates of emissions in the wide surroundings of a tower when used to interpret the variation of the concentration profile measured at the tower. A fairly crude version of such an approach has been employed in a comparison with independently estimated emissions inventories of methane with reasonable success (Vermeulen, 1997). The task is likely to be less difficult for the fossil component of $\mathrm{CO}_{2}$ than for the natural component with its strong diurnal character of photosynthesis and respiration.

Once the Kyoto (and successor) agreements have been signed and ratified, we need to have developed the methodology to independently verify emissions and to assess the effects on $\mathrm{CO}_{2}$ of land use policies. The economic stakes are very high. To attain maximum credibility we will need all of the experimental approaches and their integration mentioned in Section 3. The observational task is demanding. It is not too soon to start the development of such methods now.

\section{REFERENCES}

Bacastow, R. B., Keeling, C. D., Lueker, T. J., Wahlen, M and Mook, W. G. 1996. The 13C Suess effect in the world surface oceans and its implications for oceanic uptake of $\mathrm{CO}_{2}$ : analysis of observations at Bermuda Global Biogeochem. Cycles 10, 335-346.

Bakwin, P. S., Tans, P. P., Hurst, D. F. and Zhao, C. 1998. Measurements of carbon dioxide on very tall towers: an update of the NOAA/CMDL program. Tellus 50B, 401-406.

Baldocchi, D., Valentini, R., Running, S., Oechel, W. and Dahlman, R. 1996. Strategies for measuring and modeling carbon dioxide and water vapor fluxes over terrestrial ecosystems. Global Change Biology 2, 159-168.

Barnola, J.-M., Raynaud, D., Chappellaz, J., Barkov, N. I., Michel, E. and Jeanjean, E. 1997. Atmospheric $\mathrm{CO}_{2}$ data from the decadal to the millennium timescale over the last 400,000 years deduced from ice core studies. In: 5th International $\mathrm{CO}_{2}$ Conference, Extended abstracts. Cairns, Australia, 8-12 September 1997, p. 203.

Bender, M., Ellis, T., Tans, P., Francey, R. and Lowe, D. 1996. Variability in the $\mathrm{O}_{2} / \mathrm{N}_{2}$ ratio of southern hemisphere air, 1991-1994: implications for the carbon cycle. Global Biogeochem. Cycles 10, 9-21.

Bonan, G. 1998. The land surface climatology of the NCAR land surface model coupled to the NCAR Community Climate Model. J. Climate 11, 1307-1326.

Brewer, P., Goyet, C. and Dyrssen, D. 1989. Carbon dioxide transport by ocean currents at $25^{\circ} \mathrm{N}$ latitude in the Atlantic Ocean. Science 246, 477-479.

Broecker, W. S. and Peng, T.-H. 1992. Interhemispheric transport of carbon dioxide by ocean circulation. Nature 356, 587-589.
Broecker, W. S. 1997. Thermohaline circulation, the Achilles heel of our climate system: Will man-made $\mathrm{CO}_{2}$ upset the current balance? Science 278, 1582-1588.

Ciais, P., Tans, P. P., Trolier, M., White, J. W. C. and Francey, R. J. 1995. A large northern hemisphere terrestrial $\mathrm{CO}_{2}$ sink indicated by the ${ }^{13} \mathrm{C} /{ }^{12} \mathrm{C}$ ratio of atmospheric $\mathrm{CO}_{2}$. Science 269, 1098-1102.

Ciais, P., Denning, A. S., Tans, P. P., Berry, J. A., Randall, D. A., Collatz, G. J., Sellers, P. J., White, J. W. C., Trolier, M., Meijer, H. A. J., Francey, R. J., Monfray, P. and Heimann, M. 1997a. A three-dimensional synthesis study of $\delta^{18} \mathrm{O}$ in atmospheric $\mathrm{CO}_{2}$. (1) Surface fluxes. J. Geophys. Res. 102, 5857-5872.

Ciais, P., Tans, P. P., Denning, A. S., Francey, R. J., Trolier, M., Meijer, H. A. J., White, J. W. C., Berry, J. A., Randall, D. A., Collatz, G. J., Sellers, P. J., Monfray, P. and Heimann, M. 1997b. A three-dimensional synthesis study of $\delta^{18} \mathrm{O}$ in atmospheric $\mathrm{CO}_{2}$. (2) Simulations with the TM2 transport model. J. Geophys. Res. 102, 5873-5883.

De Baar, H. J. W., de Jong, J. T. M., Bakker, D. C. E., Loscher, B. M., Veth, C., Bathmann, U. and Smetacek, V. 1995. Importance of iron for plankton blooms and carbon dioxide drawdown in the Southern Ocean. Nature 373, 412-415.

Denning, A. S., Collatz, G. J., Zhang, C., Randall, D. A., Berry, J. A., Sellers, P. J., Colello, G. D. and Dazlich, D. A. 1996. Simulations of terrestrial carbon metabolism and atmospheric $\mathrm{CO}_{2}$ in a general circulation model. Part 1: Surface carbon fluxes. Tellus 48B, 521-542.

Denning, A. S., Holzer, M., Gurney, K. R., Heimann, M., Law, R. M., Rayner, P. J., Fung, I. Y., Fan, S.-M., Taguchi, S., Friedlingstein, P., Balkansky, Y. and 
Levin, I. 1999. Three-dimensional transport and concentration of $\mathrm{SF}_{6}$. A model intercomparison study (Transcom 2). Tellus 51B, 266-297.

Dixon, R. K., Brown, S., Houghton, R. A., Solomon, A. M., Trexler, M. C. and Wisniewski, J. 1994. Carbon pools and flux of global forest ecosystems. Science 263, $185-190$.

Doney, S. C., Glover, D. M. and Najjar, R. G. 1996. A new coupled, one-dimensional biological-physical model for the upper ocean: applications to the JGOFS Bermuda Atlantic Time Series (BATS) site. Deep-Sea Res. II 43, 591-624.

Falkowski, P. G. 1997. Evolution of the nitrogen cycle and its influence on the biological sequestration of $\mathrm{CO}_{2}$ in the ocean. Nature 387, 272-274.

Fan, S., Gloor, M., Mahlman, J., Pacala, S., Sarmiento, J., Takahashi, T. and Tans, P. 1998. A large terrestrial sink in North America implied by atmospheric and oceanic carbon dioxide data and models. Science 282, 442-446.

Farquhar, G. D., Lloyd, J., Taylor, J. A., Flanagan, L. B., Syvertsen, J. P., Hubick, K. T., Wong, S. C. and Ehleringer, J. R. 1993. Vegetation effects on the isotopic composition of oxygen in atmospheric $\mathrm{CO}_{2}$. Nature 363, 439-443.

Fasham, M. J. R. 1995. Variations in the seasonal cycle of biological production in the sub-Arctic oceans: a model sensitivity analysis. Deep-Sea Res. 142 , 1111-1149.

Francey, R. J. and Tans, P. P. 1987. Latitudinal variation in oxygen-18 of atmospheric $\mathrm{CO}_{2}$. Nature 327, 495-497.

Francey, R. J., Tans, P. P., Allison, C. E., Enting, I. G., White, J. W. C. and Trolier, M. 1995. Changes in oceanic and terrestrial carbon uptake since 1982 Nature 373, 326-330.

Fung, I., Field, C. B., Berry, J. A., Thompson, M. V., Randerson, J. T., MalmstrÖm, C. M., Vitousek, P. M., Collatz, G. J., Sellers, P. J., Randall, D. A., Denning, A. S., Badeck, F. and John, J. 1997. Carbon-13 exchanges between the atmosphere and the terrestrial biosphere. Global Biogeochem. Cycles 11, 507-533.

Goulden, M. L., Munger, J. W., Fan, S.-M., Daube, B. C. and Wofsy, S. C. 1996. Exchange of carbon dioxide by a deciduous forest: Response to interannual climate variability. Science 271, 1576-1578.

Goulden, M. L., Wofsy, S. C., Harden, J. W., Trumbore, S. E., Crill, P. M., Gower, S. T., Fries, T., Daube, B. C., Fan, S.-M., Sutton, D. J. and Munger, J. W. 1998 Sensitivity of boreal forest carbon balance to soil thaw. Science 279, 214-217.

Gruber, N., Sarmiento, J. L. and Stocker, T. F. 1996. An improved method for detecting anthropogenic $\mathrm{CO}_{2}$ in the oceans. Global Biogeochem. Cycles 10. 809-837.

Gruber, N. 1998. Anthropogenic $\mathrm{CO}_{2}$ in the Atlantic Ocean. Global Biogeochem. Cycles 12. 165-192.

Hesterberg, R. and Siegenthaler, U. 1991. Production and stable isotopic composition of $\mathrm{CO}_{2}$ in a soil near Bern, Switzerland. Tellus 43B, 197-205.
Holfort, J., Johnson, K. M., Schneider, B., Siedler, G. and Wallace, D. W. R. 1998. Meridional transport of dissolved inorganic carbon in the South Atlantic Ocean. Global Biogeochem. Cycles 12, 479-499.

Karl, D., Letelier, R., Tupas, L., Dore, J., Christian, J. and Hebel, D. 1997. The role of nitrogen fixation in biogeochemical cycling in the subtropical North Pacific Ocean. Nature 388, 533-538.

Keeling, R. F. and Shertz, S. R. 1992. Seasonal and interannual variations in atmospheric oxygen and implications for the global carbon cycle. Nature $\mathbf{3 5 8}$ 723-727.

Keeling, R. F. and Peng, T.-H. 1995. Transport of heat, $\mathrm{CO}_{2}$ and $\mathrm{O}_{2}$ by the Atlantic's thermohaline circulation. Phil. Trans. Roy. Soc. Lond. B 348, 133-142.

Keeling, C. D., Whorf, T. P., Wahlen, M. and van der Plicht, J. 1995. Interannual extremes in the rate of rise of atmospheric carbon dioxide since 1980. Nature 375, 666-670.

Law, R. M., Rayner, P. J., Denning, A. S., Erickson, D Fung, I. Y., Heimann, M., Piper, S. C., Ramonet, M., Taguchi, S., Taylor, J. A., Trudinger, C. M. and Watterson, I. G. 1996. Variations in modeled atmospheric transport of carbon dioxide and the consequences for $\mathrm{CO}_{2}$ inversions. Glob. Biogeochem. Cycles 10, 783-796.

Lloyd, J. and Farquhar, G. 1994. 13C Discrimination during $\mathrm{CO}_{2}$ assimilation by the terrestrial biosphere. Oecologia 99, 201-215.

Myneni, R. B., Keeling, C. D., Tucker, C. J., Asrar, G. and Nemani, R. R. 1997. Increased plant growth in the northern high latitudes from 1981-1991. Nature 386, 698-702.

Randerson, J. T., Thompson, M. V., Conway, T. J., Fung, I. Y. and Field, C. B. 1997. The contribution of terrestrial sources and sinks to trends in the seasonal cycle of atmospheric carbon dioxide. Global Biogeochem. Cycles 11, 535-560.

Rastetter, E. B. 1996. Validating models of ecosystem response to global change. BioScience 46, 190-198.

Raynaud, D., Jouzel, J., Barnola, J. M., Chapellaz, J. Delmas, R. J. and Lorius, C. 1993. The ice record of greenhouse gases. Science 259, 926-934.

Rayner, P. J., Enting, I. G., Francey, R. J., Langenfelds, R. L., 1999. Reconstructing the recent carbon cycle from atmospheric $\mathrm{CO}_{2}, \delta^{13} \mathrm{C}$ and $\mathrm{O}_{2} / \mathrm{N}_{2}$ observations. Tellus, this issue.

Sarmiento, J. L. and Le Quéré, C. 1996. Oceanic carbon dioxide uptake in a model of century-scale global warming. Science 274, 1346-1350.

Schimel, D., et al., 1996. Radiative forcing of climate change. In: Climate change 1995, the science of climate change (ed. J.T. Houghton, L.G. Meira Filho, B.A. Callender, N. Harris, A. Kattenberg and K. Maskell). Intergovernmental Panel on Climate Change, pp. 65-131. Cambridge University Press.

Stallard, R. F. 1998. Terrestrial sedimentation and the carbon cycle: Coupling weathering and erosion to carbon burial. Global Biogeochem. Cycles 12, 231-258. Takahashi, T., Feely, R. A., Weiss, R., Wanninkhof, R. 
Chipman, D. W., Sutherland, S. C. and Takahashi, T. T. 1997. Global air-sea flux of $\mathrm{CO}_{2}$ : an estimate based on measurements of sea-air $\mathrm{pCO}_{2}$ difference. in NAS Colloquium volume on Carbon Dioxide and Climate Change (ed. C.D. Keeling). Proc. Natl. Acad. Sci. USA 94, 8292-8299.

Tans, P. P., Berry, J. A. and Keeling, R. F. 1993. Oceanic ${ }^{13} \mathrm{C} /{ }^{12} \mathrm{C}$ observations, a new window on $\mathrm{CO}_{2}$ uptake by the oceans. Global Biogeochem. Cycles 7, 353-368.

Tans, P. P., Bakwin, P. S. and Guenther, D. W. 1996. A feasible Global Carbon Cycle Observing System: a plan to decipher today's carbon cycle based on observations. Global Change Biol. 2, 309-318.

Vermeulen, A. T., Beemsterboer, B., van den Bulk,
W. C. M., Eisma, R., Hensen, A., Kieskamp, W. M., Mols, J. J., Slanina, J., Veltkamp, A. C., Wyers, G. P. and Zwaagstra, O. 1997. Validation of methane emission inventories for NW-Europe. Report ECN-C-96-088. Netherlands Energy Research Foundation ECN, Petten, The Netherlands.

Wallace, D. W. R. 1995. Monitoring global ocean carbon inventories. Ocean observing system background report (5). Texas A\&M University, College Station, Texas, $54 \mathrm{pp}$.

Wofsy, S. C., Goulden, M. L., Munger, J. W., Fan, S.-M. Bakwin, P. S., Daube, B. C., Bassow, S. L. and Bazzaz, F. A. 1993. Net exchange of $\mathrm{CO}_{2}$ in a mid-latitude forest. Science 260, 1314-1317.

Tellus 51B (1999), 2 